This is a self-archived version of an original article. This version may differ from the original in pagination and typographic details.

Author(s): Kligler-Vilenchik, N.; Hermida, A.; Valenzuela, S.; Villi, M.

Title: Studying incidental news : Antecedents, dynamics and implications

Year: 2020

Version: Accepted version (Final draft)

Copyright: @ 2020 SAGE publications

Rights: In Copyright

Rights url: http://rightsstatements.org/page/lnC/1.0/?language=en

Please cite the original version:

Kligler-Vilenchik, N., Hermida, A., Valenzuela, S., \& Villi, M. (2020). Studying incidental news :

Antecedents, dynamics and implications. Journalism, 21(8), 1025-1030.

https://doi.org/10.1177/1464884920915372 


\title{
Studying Incidental News: Antecedents, Dynamics and Implications
}

\author{
Neta Kligler-Vilenchik, Hebrew University of Jerusalem, Israel \\ Alfred Hermida, University of British Columbia, Canada \\ Sebastián Valenzuela, Pontificia Universidad Católica de Chile, Chile \\ Mikko Villi, University of Jyväskylä, Finland
}

In light of concerns about decreasing news consumption (Ha et al., 2016), a decline in interest in political news (Aalberg et al., 2013) or even active avoidance or resistance of the news (Newman, Fletcher, Kalogeropoulos and Nielsen, 2019; Woodstock, 2013), the idea of 'incidental news' has been seen as a possible remedy. 'Incidental news' refers to the ways in which people encounter information about current events through media when they were not actively seeking the news - with the possible implication that even with decreased active seeking out of the news, citizens may remain at least somewhat informed.

The past few years have seen a significant increase in incidental news consumption on digital platforms and social media, accompanied by heightened scholarly attention to the phenomenon. Research in mass communication and political communication has examined issues related to incidental news consumption since the pioneering work of Downs (1957) sixty years ago. With the dominance of broadcast in the latter half of the 20th century, Gerbner (1987) raised the notion of the "inadvertent audience" whose perceptions of societal issues are shaped by casual exposure to news while watching television. With the advent of the commercial internet, Tewksbury and his colleagues (2001) claimed that going online lowered the barrier of access to news while browsing other types of information.

Since then, and in particular in relation to the rise of social media, there has been growing interest among scholars related to understanding the causes, dynamics, and consequences of consuming news in an incidental fashion online (e.g., Boczkowski, Mitchelstein \& Matassi, 2018; 
Fletcher \& Nielsen, 2017; Gil de Zúñiga et al., 2017; Hermida, 2014; Lee \& Kim, 2017; OeldorfHirsh, 2018; Valeriani \& Vaccari, 2016).

However, scholars studying incidental news through different theoretical and methodological perspectives have been arriving at differing evaluations of the significance and implications of this phenomenon - to the extent of downright contradictory findings (see, for example, Bode, 2016 vs. Oeldorf-Hirsch, 2018 regarding political learning). As part of this debate, the concept of incidental news itself has been questioned in terms of its usefulness, the aspects it either clarifies or obscures, and its relation to other, similar concepts, such as ambient journalism (Hermida, 2010) or the aforementioned inadvertent audience (Gerbner, 1987). This state of affairs points to the need to pause and further interrogate the phenomenon under study. What types of incidental exposure need to be distinguished, and how do they differ in terms of their outcomes? What is the salience of incidental exposure occurring among different parts of the population? When does incidental exposure lead to positive outcomes in terms of political learning, political conversation and political participation?

In this issue, our main aim is a conceptual clarification of incidental news exposure. Scholars coming from different perspectives, ranging from cognitive processing, ecological models, emergent practices, and a focus on platform affordances, show how different theoretical perspectives help account for various dimensions of incidental news consumption, and thus help explain the often conflicting findings that have been suggested so far.

\section{Studying incidental news - An overview of the special issue}

Extant research on incidental news has reached differential findings regarding the ability of such news consumption to contribute to outcomes such as political learning and participation. Coming from a cognitive processing perspective, two of the contributions in this special issue attempt to explain such variations by an explication of different stages or types of incidental news exposure. Matthes, Heiss, Nanz, and Stubenvoll (2020) suggest that incidental news exposure 
should be conceptualized as a dynamic process with two separate levels: first, the passive scanning of incidentally encountered political information for its relevance, and second, the intentional processing of incidentally encountered content deemed relevant to the reader. Based on cognitive processing theories, the model assumes that second level incidental exposure should be related to stronger outcomes in terms of political participation and knowledge. They further distinguish between incidental exposure that is intention-based - coming across the news when perusing social media for other purposes, and topic-based — coming across other political information, while searching for specific political news.

Similarly, Wieland and Kleinen-von Königslöw (2020) point out that much of the literature on incidental news consumption focuses on "successful" encounters, in which encountered information leads to knowledge and participation gains. But do we have a sufficient understanding of the process in which people skim through news on their feeds without ever actively engaging with it? The authors propose that incidental news should be conceptualized as consisting of two stages: contact within a social media newsfeed, and processing after contact. In the latter stage, three possible paths are suggested. An active path is one in which an incidental encounter with the news leads to active engagement with it, e.g. reading a full article; however two other paths may occur - an automatic base mode path (scrolling through the newsfeed), and a incidental path (brief 'snacking on the news' based on a teaser). Empirically distinguishing these different processing pathways may help explain when and why incidental news exposure leads to differential outcomes.

Another aspect of incidental news exposure that has not been sufficiently conceptualized is the question of inequality in the spread of this phenomenon. Considering incidental news exposure as a possible antidote to lack of active news consumption assumes that those with low political interest will still 'enjoy' sufficient opportunities to be incidentally exposed to news, based on the posting habits of their social network connections. Two of the special issue contributions, embodying different perspectives, call this assumption into question. Thorson (2020) conducts a 
critical review of the literature on incidental exposure, one that calls increased attention to the role played by platforms and algorithms. Discussing the interplay between user choices, the targeting behavior of news organizations, and the ways algorithms shape what users will be exposed to, Thorson shows that so-called "happy accidents" of incidental exposure may be much less ubiquitous than we assume. Instead, she suggests viewing incidental exposure through the metaphor of 'attracting the news,' which takes into account the dynamic process in which being more interested in the news leads to more engagement with news online, in turn furthering more incidental news encounters.

A similar dynamic of inequality in the salience and subsequent effects of incidental news exposure is described by Kümpel (2020). She argues that inequality may function on two levels when it comes to incidental news: users have unequal chances to be exposed to news on social network sites at all, and, once they are exposed, they are unequally likely to engage with the encountered news content. Such dynamics lead to the "Matthew Effect," where those users already interested in news will enjoy relative enrichment, while those with little or no interest in current affairs information will be further impoverished.

While the articles so far have discussed various outcomes of incidental news exposure, Barnidge (2020) focuses on a specific effect: encountering political disagreement. Barnidge's study tests the inadvertency hypothesis - the idea that on social media, people may inadvertently encounter not only news, but also political disagreement. Employing a two-wave online survey in the context of the U.S. 2018 midterm elections, Barnidge tests this hypothesis, while also considering its interplay across different platforms. The study finds that incidental news exposure is indeed positively related to political disagreement, particularly on social networking sites such as Facebook. One of the study's more surprising findings is that respondents report more incidental news exposure in traditional media than in social media-reminding us that incidental exposure is 
not limited to social media but should be considered in the context of users' full information ecology.

Such a holistic, ecological view of incidental news consumption underlies the last two contributions to this special issue. Weeks and Lane (2020) propose an ecological model, which organizes the factors influencing incidental exposure into six ecological levels, from the characteristics of individuals (cognitive ability, demographic/identity, perceptions of the information environment and level of motivation) to environmental factors (the level of the social network and the level of media systems). These factors, they claim, can be state-like-malleable and shifting depending on the individual or context; or they can be trait-like — stable and inherent. Importantly, the different factors can interact across levels, shaping both incidental exposure and its consequences.

The final contribution to this special issue employs a qualitative comparative study of incidental news consumption, examining how users across five countries encounter the phenomenon in the context of their everyday lives and their broader media consumption practices, that include not only social media but also print and broadcast media. Building on structuration theory, Mitchelstein, Boczkowski, Tenenboim-Weinblatt, Hayashi, Villi, and Kligler-Vilenchik (2020) offer an analysis of 200 semi-structured interviews, showing that — across the different national contexts - intentionality in news consumption can be viewed on a continuum, ranging from deliberately setting apart time to access the news on specific outlets, to skimming through unsought-for news on both social and broadcast media. This continuum also takes into account intermediate practices, such as setting up an environment where a user is more or less likely to encounter the news. The analysis thus shows how individual agency and social structure interact in shaping processes of information acquisition.

Taken together, these articles contribute to our understanding of the dynamics of incidental news consumption: who is more or less likely to be exposed incidentally to news, and with what 
respective outcomes; how incidental news consumption functions across different media channels, platforms and devices; and — subsequently — the differential effects of incidental news consumption such as for learning, participation, or exposure to political disagreement. At the same time, these contributions also point at questions that remain unanswered, and areas for future research. For example, from a journalism angle, what are the implications incidental news consumption raises for journalistic practices? How can and should media professionals react to an environment where capturing audience attention is not only becoming more difficult, but takes place in a particular (social) media logic?

We offer this special issue as a conceptual starting point to help cohere the study of incidental news consumption across media and communication studies, with relevance to scholars coming from journalism studies, political communication, audience studies and more. Only through more conceptual clarity can we better address the integral question of the broader implications of incidental news consumption for a healthy functioning democracy.

\section{References}

Aalberg T, Blekesaune A and Elvestad E (2013) Media choice and informed democracy: Toward increasing news consumption gaps in Europe? The International Journal of Press/Politics 18(3): 281-303.

Barnidge M (2019) Testing the inadvertency hypothesis: Incidental news exposure and political disagreement across media platforms. Journalism.

Boczkowski P, Mitchelstein E and Matassi M (2018) "News comes across when I'm in a moment of leisure": Understanding the practices of incidental news consumption on social media. New Media \& Society 20(10): 3523-3539.

Bode L (2016) Political news in the news feed: Learning politics from social media. Mass Communication and Society 19 (1): 24-48.

Downs A (1957) An economic theory of democracy. New York: Harper.

Fletcher R and Nielsen RK (2017) Are people incidentally exposed to news on social media? A comparative analysis. New Media \& Society 20(7): 2450-2468. 
Gerbner G (1987) Science on television: How it affects public conceptions. Issues in Science and Technology 3, 109-15.

Gil de Zúñiga H, Weeks B and Ardèvol-Abreu A (2017) Effects of the News-Finds-Me perception in communication: Social media use implications for news seeking and learning about politics. Journal of Computer Mediated Communication 22(3): 105-123.

Ha L, Xu Y, Yang C, Wang F, Yang L, Abuljadail M, Hu Xiao, Jiang W and Gabay I (2016) Decline in news content engagement or news medium engagement? A longitudinal analysis of news engagement since the rise of social and mobile media 2009-2012. Journalism 19(5): 718-739.

Hermida A (2010) Twittering the news: The emergence of ambient journalism. Journalism Practice, 4(3), 297-308.

Hermida A (2014) Tell everyone: Why we share and why it matters. Toronto, Canada: Doubleday.

Kümpel AS (2019) The Matthew Effect in social media news use: Assessing inequalities in news exposure and news engagement on social network sites (SNS). Journalism.

Lee JK and Kim E (2017) Incidental exposure to news: Predictors in the social media setting and effects on information gain online. Computers in Human Behavior 75: 1008-1015.

Matthes J, Heiss R, Nanz A and Stubenvoll M (2019) Processing news on social media: The political incidental exposure model (PINE). Journalism.

Mitchelstein E, Boczkowski P, Tenenboim-Weinblatt K, Hayashi K, Villi M and Kligler-Vilenchik N (2019). Incidentality on a continuum: A comparative conceptualization of incidental news consumption. Journalism.

Oeldorf-Hirsch A (2018) The Role of Engagement in Learning from Active and Incidental News Exposure on Social Media. Mass Communication and Society 21: 225-247.

Newman N, Fletcher R, Kalogeropoulos A and Nielsen, RK (2019) Reuters Institute Digital News Report 2019. Retrieved from https://reutersinstitute.politics.ox.ac.uk/sites/default/files/201906/DNR_2019_FINAL_0.pdf

Tewksbury DH, Weaver AJ and Maddex, BD (2001) Accidentally informed: Incidental news exposure on the World Wide Web. Journalism \& Mass Communication Quarterly 78(3): 533-554.

Thorson K (2019) Attracting the news: Algorithms, platforms, and reframing incidental exposure. Journalism.

Valeriani A and Vaccari C (2016) Accidental exposure to politics on social media as online participation equalizer in Germany, Italy, and the United Kingdom. New Media \& Society 18(9): 1857-1874.

Weeks B and Lane D (2019) The ecology of incidental exposure to news in digital media environments. Journalism. 
Wieland M and Kleinen-von Königslöw K (2019) Conceptualizing different forms of news processing following incidental news contact: A triple path model. Journalism.

Woodstock L (2013) The news-democracy narrative and the unexpected benefits of limited news consumption: The case of news resisters. Journalism 15(7): 834-849. 